\title{
LAPAROSCOPIC CHOLECYSTECTOMY FOR ACUTE GALLBLADDER DISEASE DURING INDEX ADMISSION-THE OPTIMUM TIMING FOR SURGERY
}

\author{
Md. Ibrahim Siddique ${ }^{1}$, Md. Atiar Rahman', Md. Shahadot Hossain Sheikh', \\ Khandker Manzoor Murshed ${ }^{1}$, Samia Mubin ${ }^{2}$, Muhammad Ali Siddiqui ${ }^{3}$, Krisna Rani Majumder ${ }^{3}$
}

\begin{abstract}
Background: Laparoscopic cholecystectomy, initially considered a contraindication for the treatment of acute gallbladder disease, is now being practiced for treating acute cholecystitis worldwide. The purpose of the study is to evaluate the outcome of laparoscopic procedure in the management of acute gallbladder disease during the index admission in terms of safety and feasibility, hospital stay and the rates of complications and conversion to open cholecystectomy.

Methods: Between January 2009 to December 2011, 174 patients (103 female, 71 male) with median age 43.5 years (range 27-73 years) with the diagnosis of acute gallbladder disease underwent laparoscopic cholecystectomy. Diagnosis of acute cholecystitis was made from history, physical findings and ultrasound evidence of acute inflammatory changes.

Results: Median time from onset of symptoms to surgery was $\mathbf{7 0}$ hours. Median operative time was 76.5 minutes. Conversion rate was $1.7 \%$. Minor post-operative complications occurred in $13.5 \%$ cases of laparoscopic procedure, which did not require further intervention. Median post-operative hospital stay was 2.5 days and total length of hospital stay was median 4.4 days. There was no mortality.

Conclusion: In expert hands laparoscopic cholecystectomy for acute gallbladder disease during the index admission is safe with better clinical results, shorter hospital stay and an acceptable conversion and complication rates with additional financial benefit to the patients.

Key words: Acute gallbladder diseases - laparoscopic cholecystectomy.
\end{abstract}

\section{Introduction}

Laparoscopic cholecystectomy is firmly established as the gold standard procedure for symptomatic gallstone disease. It has been established that urgent open cholecystectomy for acute cholecystitis is safe, can reduce hospital stay with a more rapid recovery ${ }^{1}$. In the era of laparoscopic surgery many surgeons worldwide are practicing laparoscopic cholecystectomy

1. Associate Professor, Department of Surgery, Faculty of Surgery, Bangabandhu Sheikh Mujib Medical University, Dhaka

2. Assistant Professor, Department of Surgery, Bangabandhu Sheikh Mujib Medical University, Dhaka

3. Medical Officer, Department of Surgery, Faculty of Surgery, Bangabandhu Sheikh Mujib Medical University, Dhaka

Correspondence to: Dr. Md. Ibrahim Siddique, Associate Professor, Department of Surgery, Faculty of Surgery, BSMMU, Bangabandhu Sheikh Mujib Medical University, Shahbag, Dhaka1000, E-mail: siddib777@yahoo.com

Received: 23 July $2012 \quad$ Accepted: 01 October 2012 for acute gallbladder diseases with variable results in terms of feasibility, complications and conversion to open cholecystectomy. In the pioneering days acute cholecystitis was considered a contraindication to laparoscopic surgery. However with growing experience and technical skills, a number of centers have reported that laparoscopic cholecystectomy for acute cholecystitis is technically feasible and safe, though at the expense of a high conversion rate ${ }^{2-4}$.

Traditionally, patients with acute cholecystitis have been managed conservatively in the emergency setting with planned interval cholecystectomy 6-8 weeks later. A significant number of patients have a higher readmission rate (29-40\%) whilst waiting for surgery ${ }^{5,6}$. In the context of our country this is adverse for the patients with an additional financial burden. A policy is therefore adopted to do laparoscopic cholecystectomy for patients with acute gallbladder 
diseases during the same admission and the purpose of the present study is to share our experience with others in terms of feasibility and safety, hospital stay, morbidity and mortality associated with laparoscopic procedure in acute gallbladder diseases.

\section{Patients and Methods}

Between January 2009 to December 2011, 174 patients with a diagnosis of acute cholecystitis admitted to the Department of Surgery, Bangabandhu Sheikh Mujib Medical University and two other private hospitals in Dhaka city were included in the study. The diagnosis of acute cholecystitis was based on history of acute right upper abdominal pain with or without nausea and vomiting, right upper quadrant tenderness with or without local muscle guard, elevated body temperature, leukocytosis and ultrasonographic evidences of thickwalled oedematous or distended gallbladder, presence of stones, pericholecystic fluid collections and a positive sonographic Murphy's sign. Patients unwilling to have the laparoscopic procedure, with symptoms more than a week, co-existing choledocholithiasis, biliary pancreatitis, previous upper abdominal surgery and with significant medical problems rendering them unfit for laparoscopic procedure were excluded from the study. Informed written consent was obtained with special emphasis to a need for conversion if necessary from all patients prior to their enrollment in the study. On admission all patients were started with nothing per oral, intravenous fluids, analgesics and antibiotics, commonly cephalosporins. Metronidazole was added in patients who were found to have pus on aspiration of gallbladder and gangrenous gallbladder peroperatively.

In the majority of the cases operations were done as soon as the theatre facilities were available, within 24 hours of admission. The surgery was carried out under general anaesthesia with endotracheal intubation. Pneumoperitoneum was created through an infraumbilical incision by open technique. Standard 4 port technique was adopted with two $10 \mathrm{~mm}$ ports (one infraumbilical for the telescope and one epigastric for the dissector and suction device) and two $5 \mathrm{~mm}$ ports (one at the mid-clavicular line along the right subcostal margin and the other one more laterally at the level above the umbilicus). After initial survey of the peritoneal cavity adhesionolysis was carried out by blunt (with the tip of the suction device) and sharp dissection (using unipolar cautery hook) when necessary. Distended gallbladder was decompressed by a special sucking device through the epigastric port. Calot's triangle was dissected and cystic duct and artery were skeletonized. Cystic duct and artery were divided between clips separately in most of the cases. In situations where cystic duct and artery could not be dissected separately, clips were applied close to the neck of the gallbladder securing them together. Peroperative cholangiogram was not carried out in any case. The gallbladder was dissected from the liver bed with the unipolar cautery hook. Hemostasis was ensured. The gallbladder (and the stones in case of spillage) was placed in a retrieval bag and delivered out through the epigastric port which was enlarged when necessary. After a thorough saline lavage, a subhepatic drain was kept when considered necessary and brought to the exterior through one of the $5 \mathrm{~mm}$ ports. Aponeurotic defects at umbilical and epigastric ports were closed with $1 / 0$ vicryl. Skin edges at port sites were apposed with subcuticular $3 / 0$ vicryl suture. Resected gallbladder was sent for histopathological examination.

Post-operatively pain relief was obtained initially with a single dose of intramuscular pethidine. Intravenous antibiotics were continued until the patients resumed to oral liquid. Cephalosporin and Metronidazole (when added) were continued in oral form post-operatively for 7 days and 5 days respectively. Patients were allowed oral intake 16-24 hours after surgery provided they had no nausea or vomiting and post-operative analgesia was maintained with oral paracetamol with additional diclofenac suppositories in some patients. Drains were removed after 24-72 hours of surgery when there was no further drainage. The patients were discharged when they were ambulant, taking normal diet and were afebrile.

Data were collected prospectively and included patient demographics and baseline characteristics, peroperative findings, technical problems, operative time, conversion to open cholecystectomy, length of post-operative stay, post-operative complications and total hospital stay. Variables and results were presented as median value, range and percentage.

\section{Results}

Total 174 patients underwent laparoscopic cholecystectomy for acute gallbladder diseases from January 2009 to December 2011. Patients demographic and baseline characteristics are presented in table-1. There were 103 female and 71 male patients with median age of 43.5 years (range, 
27-73 years). Associated medical problems were found in $63.8 \%$ patients. Median duration of symptoms prior to hospitalization was 36.5 hours (range, $12-84$ hours). More than $60 \%$ patients had previous biliary symptoms. Laboratory findings and ultrasound studies were consistent with the provisional diagnosis.

Median time from onset of symptoms to surgery was 70 hours (Table-2). More than eighty five percent of the patients had omental adhesions and thick-walled distended gallbladder. Significant number of patients (26.4\%) had gangrenous gallbladder and empyema. Around $90 \%$ of the patients needed decompression of gallbladder to facilitate instrumental handling, grasping the gallbladder and to ease dissection at Calot's triangle. None of the patients required blood transfusion. Minor bile duct injury occurred in one patient who was managed successfully by open cholecystectomy and repair of the tear. Drains were kept in the subhepatic space in most of the patients and epigastric port site had to be enlarged in onethird of the patients to deliver out the gallbladder.
Median operative time was 76.5 minutes (range 50145 minutes). Three male patients (1.7\%) underwent conversion to open cholecystectomy. The reasons for conversion in two cases were difficult dissection at Calot's triangle due to dense adhesions with unclear anatomy. Third one underwent conversion to repair a minor tear in the CBD. All these three patients had uneventful recovery. Most of the patients were allowed oral liquid from 16 to 24 hours after the procedure with normal diet on the same day. Drains were removed after a median 1.8 days. Post-operative complications were noted in $13.5 \%$ patients and were dealt with medical treatment without any further intervention.

Median post-operative hospital stay was 2.5 days (range, 2-5 days) and median total hospital stay was 4.4 days (range 4-7 days) in successful laparoscopic patients. Laparoscopic success rate was $98.3 \%$. Histopathological analysis of resected gallbladder revealed acute cholecystitis, acute on chronic cholecystitis and gangrenous cholecystitis in $60.9 \%, 25.9 \%$ and $13.2 \%$ cases respectively. There was no death in this series.

Table-I

Patient demography and baseline characteristics $(n=174)$

\begin{tabular}{|c|c|}
\hline Variable & Number of Patients (\%) \\
\hline Gender & $103 \mathrm{~F}, 71 \mathrm{M}$ \\
\hline Age (years) ${ }^{a}$ & $43.5(27-73)$ \\
\hline Body mass index $\left(\mathrm{kg} / \mathrm{m}^{2}\right)^{a}$ & $17.5(16-23)$ \\
\hline Duration of symptoms (hours) ${ }^{a}$ & $36.5(12-84)$ \\
\hline Previous biliary symptoms & $112(64.4 \%)$ \\
\hline temperature $\left({ }^{\circ} \mathrm{F}\right)^{a}$ & $99.6(98.4-101.6)$ \\
\hline Total leukocyte count (cells $\left./ \mathrm{mm}^{3}\right)^{a}$ & $12700(10200-17400)$ \\
\hline Elevated C-reactive protein $(\mathrm{mg} / \mathrm{L})^{a}$ & $48(12-96)$ \\
\hline \multicolumn{2}{|l|}{ Abdominal findings } \\
\hline Tenderness and guarding in right hypochondrium & $104(59.8 \%)$ \\
\hline Mass in right upper quadrant & $29(16.7 \%)$ \\
\hline Positive Murphy's sign & $41(23.6 \%)$ \\
\hline \multicolumn{2}{|l|}{ Associated medical problems } \\
\hline Diabetes & $32(18.4 \%)$ \\
\hline Hypertension & $51(29.3 \%)$ \\
\hline Heart disease & $24(13.8 \%)$ \\
\hline Obstructive airway disease & $02(1.15 \%)$ \\
\hline Impaired renal function & $02(1.15 \%)$ \\
\hline \multicolumn{2}{|l|}{ Ultrasound findings } \\
\hline Thick-walled oedematous gallbladder & $145(83.3 \%)$ \\
\hline Distended gallbladder & $112(64.4 \%)$ \\
\hline Presence of gallstones & $166(95.4 \%)$ \\
\hline Pericholecystic collections & $53(30.5 \%)$ \\
\hline Positive sonographic Murphy's sign & $141(81 \%)$ \\
\hline
\end{tabular}

a Median values (range), F, Female; M, Male. 
Table-II

Perioperative data $(n=174)$

\begin{tabular}{lc}
\hline Operative details & Number of Patients (\%) \\
\hline Time from onset of symptoms to surgery (hours) & a \\
Peroperative findings & $70(42-110)$ \\
Omental adhesions & $155(89 \%)$ \\
Distended thick-walled gallbladder & $151(86.8 \%)$ \\
Gangrenous gallbladder & $23(13.2 \%)$ \\
Inflammatory exudates in right subhepatic space or paracolic gutter & $98(56.3 \%)$ \\
Pus on aspiration of gallbladder & $23(13.2 \%)$ \\
Difficult dissection to release adhesions & $42(24.1 \%)$ \\
Need for gallbladder decompression & $155(89 \%)$ \\
Gallbladder perforation with spillage of contents & $17(9.8 \%)$ \\
Difficult dissection at Calot's triangle & $25(14.4 \%)$ \\
Difficult dissection at gallbladder bed & $22(12.6 \%)$ \\
Estimated blood loss (ml) & \\
Bile duct injury & $27.5(10-150)$ \\
Enlargement of epigastric port site & $01(0.6 \%)$ \\
Use of drains & $56(32.2 \%)$ \\
Operative time (minutes) & $152(87.4 \%)$ \\
Conversion to open cholecystectomy & $76.5(50-145)$
\end{tabular}

${ }^{a}$ Median values (range) expressed

Table-III

Post-operative course and outcome (n-171) (excluding the patients who had conversion)

\begin{tabular}{lc} 
Variables & No. of patients (\%) \\
\hline Post-operative complications & \\
$\quad$ Paralytic ileus & $03(1.75 \%)$ \\
$\quad$ Port site hematoma & $07(4.0 \%)$ \\
$\quad$ Wound infection & $13(7.6 \%)$ \\
Oral resumption (hours) $^{\mathrm{a}}$ & $18.5(16-24)$ \\
Removal of drains (days) $^{\mathrm{a}}$ & $1.8(1-3)$ \\
Post-operative length of stay (days) $^{\mathrm{a}}$ & $2.5(2-5)$ \\
Total length of hospital stay (days) $^{\mathrm{a}}$ & $4.4(4-7)$ \\
Successful laparoscopic $^{\text {cholecystectomy }}$ & $98.3 \%$ \\
\hline
\end{tabular}

a Median values (range) expressed

\section{Discussion}

Acute cholecystitis occurs in upto $10 \%$ patients with gallstones and is more likely if gallstones have previously being symptomatic ${ }^{7}$. Diagnostic criteria for acute cholecystitis, according to Tokyo guidelines are the presence of one local sign or symptom (Murphy's sign, pain or tenderness in the right upper quadrant, mass in the right upper quadrant), one systemic sign (Fever, leukocytosis, elevated C-reactive protein level) and a confirmatory finding on an imaging test (ultrasonography or hepatobiliary scientigraphy) ${ }^{8,9}$. Diagnostic characteristics of acute cholecystitis by ultrasonography are a thick walled $(>3 \mathrm{~mm}$ ) often distended gall bladder containing gallstones (one of which may be impacted in hartman's pouch) and pericholecystic fluid collections ${ }^{10}$. Most patients respond to conservative treatment with analgesics, intravenous fluids, gastrointestinal rest and antibiotic therapy and a planned elective cholecystectomy is carried out at an interval of 6-8 weeks. However this strategy has been questioned for several reasons. There is a high rate of morbidity amongst patients during this interval with higher readmission rate (29-40\%) with an additional financial burden to the patients ${ }^{5,6,11}$.

As it has already been established that urgent open cholecystectomy for acute cholecystitis is safe leading to shorter hospital stay with more rapid 
recovery, laparoscopic procedure has evolved for its minimally invasive nature. In the early years, laparoscopic cholecystectomy was considered contraindicated in acute cholecystitis. It was assumed that acutely inflamed gallbladder with its friable nature, presence of adhesions, technical difficulties, excessive bleeding and a distorted anatomy at Calot's triangle might result in more peroperative complications with injury to biliary tree leading to significant morbidity. Resolution of acute inflammatory process may facilitate a successful elective surgery later on at 6-8 weeks interval. Four randomized trials on total 398 patients comparing urgent versus interval laparoscopic cholecystectomy for acute calculous cholecystitis showed that urgent laparoscopic surgery for acute cholecystitis takes the same length of time, with similar complication rates as interval laparoscopic cholecystectomy but significantly reduces hospital stay $^{12}$.

In our study, median duration of symptoms of acute cholecystitis was 36.5 hours and median time from onset of symptoms to surgery was 70 hours with median operative time being 76.5 minutes (50-145 minutes). Feasibility of laparoscopic procedure and operative time depends on a number of factors. Experience and skill of the surgeon, difficulties in releasing adhesions peroperatively, excessive oozing or bleeding, instrumental handling of a distended thickwalled often friable gall bladder, need for gallbladder decompression and spillage of gall bladder contents are important determinants for operative time. In earlier years, several studies reported mean operation time ranging from 60 minutes to 108.2 minutes ${ }^{13,14}$.

Bile duct injury is the most serious complication during cholecystectomy, leading to conversion and is associated with significant morbidity. In our study we have one patient $(0.6 \%)$ with a minor bile duct injury who was managed successfully by open cholecystectomy and repair of the tear with an uneventful recovery. There is a general belief that initial conservative treatment for acute cholecystitis increases the chance of successful laparoscopic cholecystectomy at a later date, for the ducts are more easily displayed at this stage. This is probably not true as severe attack of acute cholecystitis involving the tissues outside the gallbladder results in the formation of an inflammatory mass which resolves slowly and if cholecystectomy is delayed, dense scar tissue will have formed between Hartman's pouch and the common bile duct, rendering exposure of the ducts far from easy.

Three patients $(1.7 \%)$ underwent conversion to open cholecystectomy in our series, two for difficult dissection with unclear anatomy and the other one for managing a minor tear in CBD. In a similar study carried out between June 2003 to March 2008 on 125 patients with acute cholecystitis treated with laparoscopic cholecystectomy, conversion rate was $7.2 \%$ in our hand ${ }^{15}$. Conversion rate in four randomized controlled trials were found $11 \%-31 \%$ where laparoscopic cholecystectomy was performed within $72-96$ hours and $23 \%-29 \%$ where the procedure was performed at an interval of 6-12 weeks ${ }^{12}$.

Early cholecystectomy has been variably defined as anywhere from 24 hours to 7 days after the onset of symptoms. However, there is a general agreement that urgent cholecystectomy is defined as the procedure being carried out within 72-96 hours of the onset of acute symptoms, delayed after 72-96 hours but during index admission and interval, when a planned cholecystectomy is carried out at an interval of 6-12 weeks after the acute condition subsides with conservative treatment ${ }^{16}$. In the first $72-96$ hours, the inflammatory changes around the gallbladder tend to be oedematous with preservation of tissue planes facilitating dissection and removal of gallbladder. After this time frame, progressive inflammatory reaction with subsequent fibrosis obliterates tissue planes ${ }^{17}$. Several studies comparing urgent (within 72-96 hours) versus delayed (beyond 72-96 hours but during the index admission) laparoscopic cholecystectomy in acute cholecystitis reported a significant increase in conversion rates from 0-27\% (urgent group) to $17-60 \%$

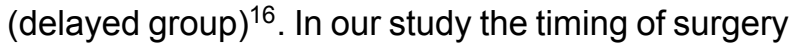
appears to be optimum, median 70 hours (range, 42110 hours). However, the timing of surgery is not the only predictor for conversion. Male sex, advancing age, obesity, gallbladder wall thickening, presence of a palpable gallbladder and complicated cholecystitis are also important determinants ${ }^{18}$.

In our study minor post-operative complications occurred in a small number of patients. There was no mortality. Median length of postoperative stay was 2.5 days and total length of hospital stay was 4.4 days in patients where the procedure was completed with laparoscopic surgery. Conversion rate was $1.7 \%$. We do not consider conversion as a complication or an operative failure rather it should be appreciated as 
a good surgical judgment. In our study there were a significant number of patients ( $26.4 \%$ ) who were found to have empyema and gangrene of gallbladder. These patients required more operative time because of the additional effort in releasing adhesions, difficulties in grasping the fundus of thick-walled, oedematous or friable gallbladder for retraction, excessive oozing and bleeding repeatedly obscuring the field of vision, frequent perforation of a tense distended or a gangrenous gallbladder with spillage of gallbladder contents and their subsequent removal, additional time for irrigation suction and for enlarging the epigastric portsite for removing a larger thick-walled gallbladder. These patients also required a longer post-operative hospital stay because of keeping drains for an additional time. Earlier operation in these cases would have been technically easier with a shorter hospital stay and least chance of developing post-operative complications.

\section{Conclusion}

In the experienced hand, laparoscopic cholecystectomy for acute gallbladder diseases is safe and appears to be technically easier within 7296 hours of acute attack developing. Surgery in the acute phase will often prevent gangrene and perforation of gallbladder which carry a significant morbidity and mortality. Better clinical results, shorter hospital stay and acceptable conversion and complication rates could be achieved in expert hands. The great advantage to the patients in operating in the acute phase is that they require only one hospital admission thus avoiding the morbidity associated with failed conservative treatment with prolonged hospital stay and recurrent symptoms requiring emergency surgery with additional financial burden to the patients. We, therefore, consider laparoscopic cholecystectomy as the procedure of choice for acute gallbladder diseases during the index admission.

\section{References:}

1. Cameron IC, Chadwick C, Phillips J, Johnson AG. Management of acute cholecystitis in UK Hospitals: time for a change. Postgrad Med J 2004; 80: 292-4.

2. Kum CK, Goh PMY, Isaac JR, Te-Kant Y, Ngoi SS. Laparoscopic cholecystectomy for acute cholecystitis. Br J Surg 1994; 81: 1651-4.
3. Willsher PC, Sanabria JR, Gallinger S, Rossi L, Strasberg S, Litwin DE. Early laparoscopic cholecystectomy for acute cholecystitis: a safe procedure, J Gastrointest Surg, 1999; 3: 50-3.

4. Lau H, Lo CY, Patil NG, Yuen WK. Early versus delayed - interval laparoscopic cholecystectomy for acute cholecystitis: a meta analysis. Surg Endosc 2006; 20: 82-7.

5. Cheruvu CV, Eyre-Brook IA. Consequences of prolonged wait before gallbladder surgery. Ann $R$ Coll Surg Engl. 2002; 84: 20-2.

6. Cameron IC, Chadwick C, Phillips J, Johnson AG. Acute cholecystitis - room for improvement? Ann R Coll Surg Engl 2002; 84: 10-13.

7. Friedman GD. Natural history of asymptomatic and symptomatic gallstones. Am J Surg 1993; 165: 399-404.

8. Takada T, Kawarada Y, Nimura $Y$, et al. Background: Tokyo guidelines for the management of acute cholangitis and cholecystitis. J Hepatobiliary Pancreat Surg. 2007; 14: 1-10.

9. Hirota M, Takada T, Kawarada Y et al. Diagnostic criteria and severity assessment of acute cholecystitis : Tokyo guidelines. J. Hepatobiliary Pancreat Surg, 2007; 14: 78-82.

10. Rubens DJ. Hepatobiliary imaging and its pitfalls. Radiol Clin North Am. 2004; 42: 257-78.

11. Somasekar K, Shankar PJ, Foster ME, Lewis $\mathrm{MH}$. Costs of waiting for gallbladder surgery. Postgrad Med J. 2002; 78: 668-9.

12. Bhattacharya D, Ammori BJ. Contemporary minimally invasive approaches to the management of acute cholecystitis : a review and appraisal. Surg Laparosc Endosc Percutan Tech. 2005; 15: 1-8.

13. Eldar S, Eitan A, Bickel A, Sabo E, Cohen A, Abrahamson J, Matter I. The impact of patient delay and physician delay on the outcome of laparoscopic cholecystectomy for acute cholecystitis. Am J Surg, 1999; 178: 303-7.

14. Kiviluoto T, Siren J, Luukkonen P, Kivilaakso E. Randomised trial of laparoscopic versus open 
cholecystectomy for acute and gangrenous cholecystitis. Lancet, 1998; 351:321-5.

15. Atiar MR, Murshed KM, Siddique MI, Sheikh $\mathrm{MSH}$. Early laparoscopic cholecystectomy in acute gallbladder disease - its safety and fasibility. J Surg Sci. 2008; 12:8-12.

16. Armstrong T, Pain JA. Acute gallbladder disease. In: Taylor I, Johnson CD (editors). Recent advances in surgery. $30^{\text {th }}$ ed. Royal Society of Medicine Press Ltd. London, UK. 2007; 93-103.

17. Indar AA, Beckingham IJ. Acute cholecystitis. BMJ 2002; 325: 639-43.

18. Liu TH, Consorti ET, Mercer DW. Laparoscopic cholecystectomy for acute cholecystitis: technical considerations and outcome. Semin Laparosc Surg. 2002;9;24-31. 